\title{
Ciliary body metastasis in a patient with non-small cell lung carcinoma — incidental detection with ${ }^{18}$ F-FDG PET/CT
}

Sellam Karunanithi ${ }^{1}$, Partha Sarathi Chakraborty', Varun Singh Dhull'1, Jeyaseelan Nadarajah², Nitesh R. Salunkhe ${ }^{3}$, Rakesh Kumar 'Department of Nuclear Medicine, All India Institute of Medical Sciences, New Delhi, India 2Department of Radiology, All India Institute of Medical Sciences, New Delhi, India ${ }^{3}$ Department of Ophthalmology, All India Institute of Medical Sciences, New Delhi, India

[Received 3 X 2013; Accepted 7 I 2014]

\begin{abstract}
Ciliary body metastasis in a case of lung cancer is very rare. Intraocular metastasis by any cancer most commonly involves choroid followed by iris and ciliary body. We present a case of a 71 -year-old male with non-small cell lung cancer who was found to have an ${ }^{18} \mathrm{~F}-\mathrm{FDG}$ avid right lung mass. Incidentally a focus of abnormal increased ${ }^{18} \mathrm{~F}-\mathrm{FDG}$ uptake was noted in the region of ciliary body in the right eyeball. The findings were confirmed to be a metastatic lesion in ciliary body on Ultrasonography and MRI. Our case depicts this extremely rare occurrence corroborated by various modalities.
\end{abstract}

KEY words: ${ }^{18} \mathrm{~F}-\mathrm{FDG}$; PET/CT, ciliary body metastasis, lung carcinoma

Nuclear Med Rev 2014; 17, 1: 40-43

\section{Introduction}

Lung cancer has been reported to metastasize to the eye in $0.2 \%$ to $7 \%$ of patients from clinical studies [1] and in $6 \%$ to $7 \%$ of patients from post-mortem histopathological studies [2]. The choroid is the most common ocular tissue affected by metastatic disease followed by iris and ciliary body [3, 4]. Of 950 uveal metastases in the study by Shields et al. [3], metastases to iris occurred in $9 \%$ cases, and to the ciliary body in $2 \%$ cases. Here we report a case that presented with right non-small-cell lung carcinoma (NSCLC) and was diagnosed to have ciliary body metastasis incidentally on ${ }^{18} \mathrm{~F}$-Fluorodeoxyglucose $\left({ }^{18} \mathrm{~F}-\mathrm{FDG}\right)$ positron emission tomography/computed tomography (PET/CT) study.

\section{Case report}

A 71-year-old male who was a chronic (50 years) smoker presented with gradually progressive shortness of breath and cough without expectoration for 6 months. His chest roentgenogram revealed bilateral apical and right mid-zone opacities. His biopsy from the right lung mass revealed NSCLC. He was referred for

Correspondence to: Dr. Rakesh Kumar, MD, PhD

E-81, Ansari Nagar (East)

AlIMS Campus, New Delhi-110029, India

Phone: 91-11-26594472

Fax: 91-11-26588663

E-mail: rkphulia@yahoo.com
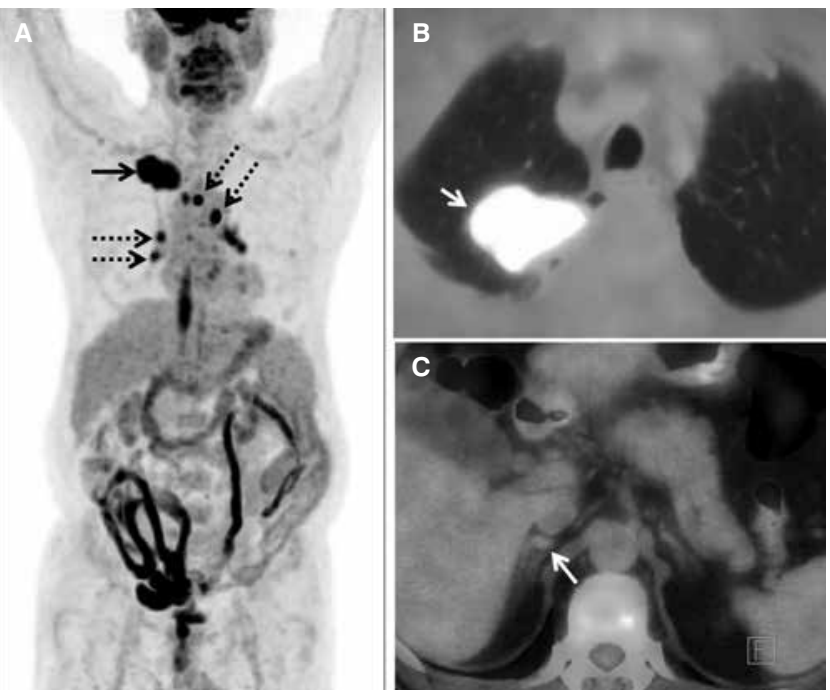

Figure 1. ${ }^{18} \mathrm{~F}-\mathrm{FDG} \mathrm{PET} / \mathrm{CT}$ whole body maximum intensity projection (MIP) and transaxial PET/CT image shows the presence of abnormal radiotracer uptake in the primary right lung mass (A, B, arrow).

Increased radiotracer uptake is also seen in the mediastinal lymph nodes (A, broken arrow) and right adrenal metastatic lesion (C, arrow)

${ }^{18}$ F-FDG PET/CT scan for initial staging. On PET/CT a right lung upper lobe primary malignant mass lesion measuring $48 \mathrm{~mm}$ in greatest dimension with intense ${ }^{18} \mathrm{FDG}$ uptake was present (SUVmax-22.5). ${ }^{18} \mathrm{FDG}$ avid metastatic lesions in mediastinal lymph 

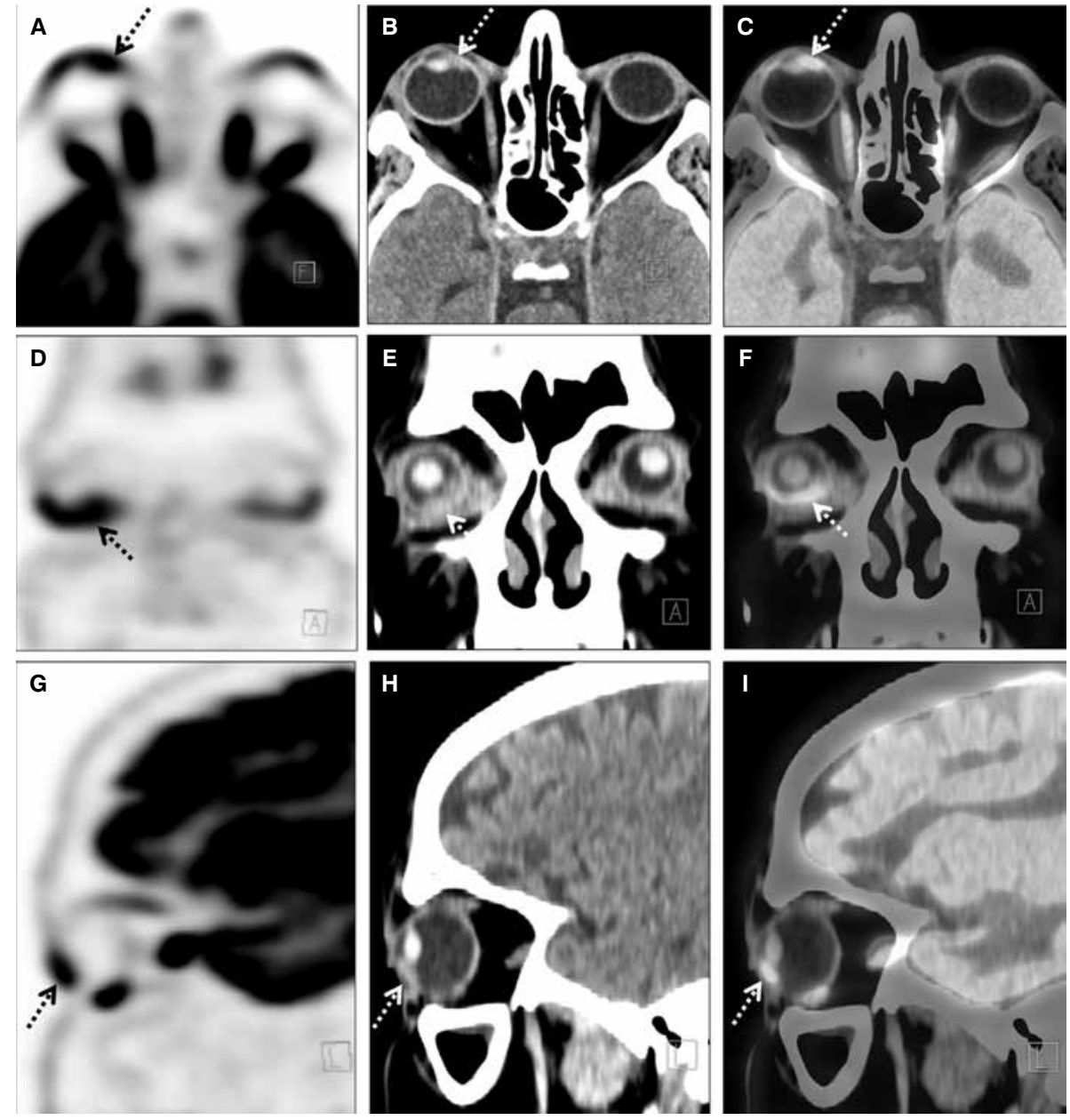

Figure 2. ${ }^{18} \mathrm{~F}-\mathrm{FDG}$ PET, CT and fused PET/CT images in transaxial, coronal and sagittal sections revealing a focus of intense ${ }^{18} \mathrm{~F}-\mathrm{FDG}$ uptake in the anterior chamber of right eye ball in the region of ciliary body (A-I, arrows)
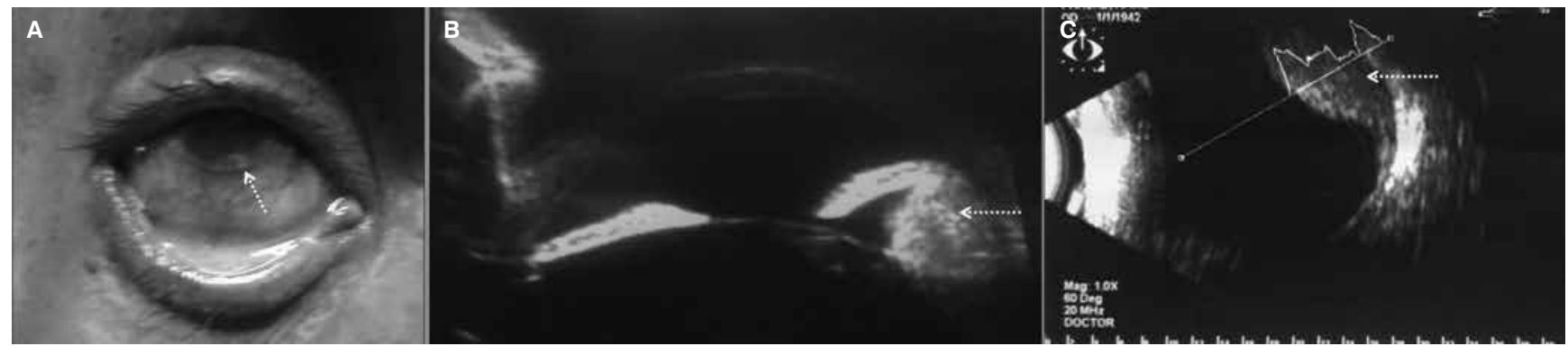

Figure 3. On clinical examination of the right eye, nodular lesion in the inner inferior quadrant of the right eye with conjunctival congestion was noted (A, arrow). Ultrasonography of the right eye revealed a mass lesion infero-medially in the region of ciliary body with internal homogeneous echogenicity with no excavation (B, C, arrow)

nodes and right adrenal gland were documented (Figure 1). Incidentally noted was the presence of ${ }^{18} \mathrm{~F}-\mathrm{FDG}$ avid nodular opacity in the inner-inferior quadrant in the anterior chamber of eyeball in the region of ciliary body (Figure 2). A provisional diagnosis of ciliary body metastasis was made. On clinical examination of the right eye, nodular lesion in the inner-inferior quadrant of the right eye with conjunctival congestion was noted. Also, anterior chamber of right eye was found to be irregular and shallow nasally (Figure 3A). An ultrasonography of the right eye was performed which revealed a mass lesion infero-medially in the region of ciliary body with internal homogeneous echogenicity with no excavation (Figure 3B, C). Kappa sign was positive. MRI of the right orbit was performed which revealed well defined enhancing right intraocular mass involving the ciliary body measuring $12{ }^{*} 10 \mathrm{~mm}$ in size, infero-medially to the lens appearing hyperintense on T1 and hypointense on T2 weighted images (Figure 4), confirming metastasis. The right lacrimal gland was bulky. The patient is currently undergoing chemotherapy. 

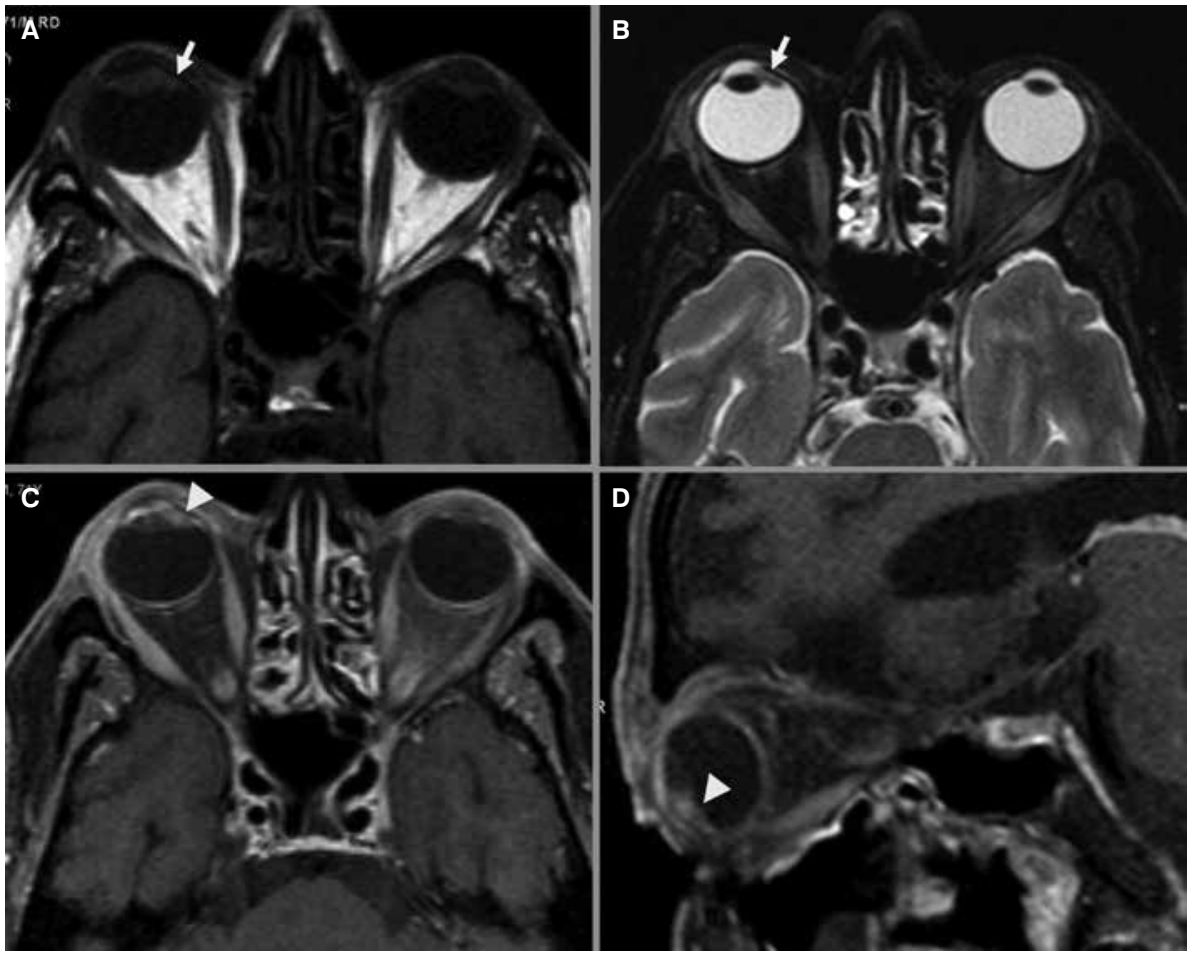

Figure 4. Axial T1 W (A) and T2 W (B) image at the level of lens show well defined tiny T1 hyper intense, T2 hypo intense nodule in ciliary body in inferonasal quadrant (arrow). Axial (C) and Oblique Sagittal (D) Contrast enhanced MR image show faint enhancement of ciliary body mass in inferonasal quadrant (arrow head)

\section{Discussion}

Metastases represent the most common form of intraocular malignancy with the most common primaries being breast and lung. Kreusel et al. [5] estimated choroid to be the sixth most common site of metastasis from lung cancer. Metastatic cancers most commonly involve posterior choroid with only $5 \%$ to $11 \%$ showing ciliary body or iris involvement [6]. Veal metastases involve the choroid more often than the iris and ciliary body, probably because the arterial distribution is more abundant in the posterior than in the anterior uvea [7]. In an analysis of 520 eyes with uveal metastasis, the most common primary site was found to be breast cancer in women and lung cancer in men [3]. In a recent analysis with 374 uveal metastatic tumors from primary lung cancer, choroid was the most common site (88\%), followed by iris (10\%) and ciliary body $(2 \%)$ with bilateral involvement in18\% [4]. Ciliary body tumors are usually dome shaped with an episcleral sentinel vessel. Other differential diagnosis can be melanoma or adenocarcinoma arising from the ciliary body which may arise from pigmented or non-pigmented ciliary epithelium [8]

Tumor metastases to iris and ciliary body can be the first sign of primary cancer and it is often very difficult to distinguish between primary neoplasia and metastasis. Studies have reported between $63 \%$ and $72 \%$ of patients with a diagnosis of uveal metastasis from lung cancer to not have a known diagnosis of lung cancer at presentation [1]. In a study with evaluation of 142 patients with uveal metastasis, lung cancer was shown as the most common primary site (35\%), followed by breast cancer ( $7 \%$ ), gastrointestinal cancer (1\%), and prostate cancer (1\%); primary cancer was undetermined in $51 \%$ [3]. These findings suggest that the presence of uveal me- tastasis in a patient with unknown primary should prompt a thorough investigation for lung cancer.

Ocular metastasis is a feature of disseminated lung cancer. So a systemic screening of asymptomatic patients for intraocular metastasis does not significantly contribute to patient outcome due to limited survival of the patients [9]. But for symptomatic patients, ophthalmic screening of patients with lung cancer is advised [1]. The mean life expectancy after detection of uveal metastases has been calculated to $7.5-13$ months $[4,5]$. Systemic prognosis is usually poor, with cancer-related death in $54 \%$ of patients by 1 year from the diagnosis of uveal metastasis [5].

Although the utility of ${ }^{18} \mathrm{~F}-\mathrm{FDG} \mathrm{PET} / \mathrm{CT}$ in the evaluation of intraocular metastases has been documented [10], the role of ${ }^{18}$ F-FDG PET/CT for detecting metastatic lesion to ciliary body has not been previously reported. In view of high physiological uptake in brain and optic nerve, one might tend to miss the pathological lesions in ocular region especially in iris and ciliary body region. Our case highlights the importance of screening the eyeball region for any abnormal uptake in patients with lung carcinoma and if present should be further evaluated as focal ${ }^{18} \mathrm{~F}-\mathrm{FDG}$ uptake in region of ciliary body/anterior chamber on $\mathrm{PET} / \mathrm{CT}$ might represent metastasis.

\section{References}

1. Su HT, Chen YM, Perng RP. Symptomatic ocular metastases in lung cancer. Respirology 2008; 13: 303-305.

2. Eliassi-Rad B, Albert DM, Green WR. Frequency of ocular metastases in patients dying of cancer in eye bank populations. Br J Ophthalmol 1996; 80: 125-128. 
3. Shields CL, Shields JA, Gross NE, Schwartz GP, Lally SE. Survey of 520eyes with uveal metastases. Ophthalmology 1997; 104: 1265-1276.

4. Shah SU, Mashayekhi A, Shields CL et al. Uveal Metastasis from Lung Cancer: Clinical Features, Treatment, and Outcome in 194 Patients. Ophthalmology. 2013 Aug 26. [Epub ahead of print] doi: 10.1016/j.ophtha.2013.07.014.

5. Kreusel KM, Wiegel T, Stange M, Bornfeld N, Hinkelbein W, Foerster MH. Choroidal metastasis in disseminated lung cancer: frequency and risk factors. Am J Ophthalmol 2002; 134: 445-447.

6. Lieb WE, Shields JA, Shields CL, Spaeth GL. Mucinous adenocarcinoma metastatic to the iris, ciliary body, and choroid. Br J Ophthalmol 1990; 74: 373-376.

7. Moura LR, Yang YF, Ayres B, Brasil OM, Fernandes BF, Burnier MN Jr. Clinical, histologic, and immunohistochemical evaluation of iris me- tastases from small cell lung carcinoma. Can J Ophthalmol 2006; 41 : 775-777.

8. Sui RF, Zhao JL, Zhang SH et al. Metastatic tumor to the iris and ciliary body as an initial sign of lung cancer: a case report. Chin Med $\mathrm{J}$ (Engl) 2005; 118: 1131-1133.

9. Kreusel KM, Wiegel T, Stange M, Bornfeld N, Hinkelbein W, Foerster MH. Choroidal metastasis in disseminated lung cancer: frequency and risk factors. Am J Ophthalmol 2002; 134: 445-447.

10. Manohar K, Mittal BR, Kulkarni P, Singh N, Bhattacharya A, Gupta A. Usefulness of F-18 FDG PET/CT as one stop shop imaging modality for diagnosis of occult primary and estimation of disease burden in patients with intraocular masses. Clin Nucl Med 2012; 37: 200-203. 